\title{
LA EXPERIENCIA DE ESTUDIANTES DE CONTEXTOS VULNERABLES EN DIFERENTES INSTITUCIONES DE EDUCACIÓN SUPERIOR UNIVERSITARIA (IESU): RESULTADOS DE INVESTIGACIÓN ${ }^{1}$
}

\author{
Daniel Leyton, Alba Vásquez, Valentina Fuenzalida²
}

\begin{abstract}
RESUMEN
El presente artículo ofrece los principales resultados de una investigación acerca de las experiencias de integración social y académica de estudiantes provenientes de contextos vulnerables en universidades chilenas. Para efectos del siguiente estudio, estas se categorizaron en cuatro tipos: universidad de élite, académica pluriclasista, no-académica pluriclasista y universidad de estratos bajos. La investigación se trabajó sobre la base del análisis de entrevistas realizadas a 29 alumnos pertenecientes a dichos contextos sociales. Los alcances más destacados muestran que en la universidad de élite domina en estos alumnos una experiencia de desclasamiento y negación de sus orígenes sociales como una estrategia para integrarse a la institución; en la universidad académica pluriclasista, en tanto, se evidencia una alta integración académica expresada en sus compromisos y transformación de sus prácticas de estudio y en donde, además, comparte con la universidad no-académica pluriclasista, conjuntamente, una clausura social y una percepción positiva de la heterogeneidad social. Por último, en la universidad de estratos bajos se hallaron precarios niveles de integración social y académica, a pesar de la identidad de clases existente entre los estudiantes.
\end{abstract}

Palabras clave: habitus institucional, integración social y académica, capital cultural, desclasamiento social, clase social

\section{THE EXPERIENCE OF STUDENTS IN VULNERABLE CONTEXTS IN DIFFERENT UNIVERSITY HIGHER EDUCATION INSTITUTIONS (IESU, BY THE SPANISH ACRONYM): RESEARCH OUTCOMES}

\section{ABSTRACT}

This paper presents the main results of a study about students' experiences in social and academic integration in 4 different types of universities. Results are based primarily in 29 interviews to students from vulnerable social backgrounds. The main findings show that in the elite university it dominates a declass experience as an integration strategy marked by denying social origins. In the academic and non-academic multi-class universities, the experiences are featured by social closure along with positive perception of social heterogeneity. In turn, in the academic multi-class university, high academic integration is expressed in their commitments and transformations of their study practices. Finally, at the lower-class university, there are precarious levels of social and academic integration despite the existing class identity among students.

Keywords: institutional habit, social and academic integration, cultural capital, social declass, social class

1 El escrito presentado a continuación corresponde a los resultados del proyecto de investigación titulado "La experiencia social y académica de estudiantes de contextos vulnerables en diferentes instituciones de educación superior", financiado por el Consejo Nacional de Educación (CNED) a partir de la concurso del año 2011 de apoyo a la investigación en educación superior.

2 Los tres autores pertenecen a la Universidad Alberto Hurtado, CIDE. Contacto:dleyton@cide.cl 


\section{LA EXPERIENCIA DE ESTUDIANTES DE CONTEXTOS VULNERABLES EN DIFERENTES INSTITUCIONES DE EDUCACIÓN SUPERIOR UNIVERSITARIA (IESU): RESULTADOS DE UNA INVESTIGACIÓN}

\section{El problema}

A partir de la década de los ochenta se configuran los procesos de masificación y segmentación social del sistema de educación superior en Chile. La masificación se caracteriza por una expansión significativa del número de universidades y matrículas, que incorporan a estudiantes no pertenecientes a la élite. Por su parte, la segmentación se caracteriza por una continua desigualdad en las tasas de acceso a la universidad y retención, y una segmentación de clase según las universidades de destino de los estudiantes (Brunner y Uribe, 2007; Brunner, 2009a; Donoso y Cansino, 2007; Canales y de los Ríos, 2009; Meneses, 2010).

Este proceso de masificación segmentada está marcado por el desarrollo de una jerarquización de las posiciones que ocupan las diferentes universidades, basada en la apropiación desigual del prestigio a través de la acumulación de capital simbólico obtenido mediante la atracción de estudiantes provenientes de diferentes orígenes sociales. Se configura así un diseño institucional que ayuda a preservar las desigualdades existentes (Ayalon, H., Grodsky, E., Gamoran, A. \&Yogev, A. 2008), sobrerrepresentando a los estudiantes de estratos altos y subrepresentando a los estudiantes de orígenes vulnerables (Brunner 2009b; OCDE, 2009; Meneses et al., 2010)3.

3 El 70\% del total de la matrícula de universidades privadas pertenece a los estudiantes de los quintiles más favorecidos, mientras que en las universidades del Consejo de Rectores de Universidades Chilenas, CRUCH, estos estudiantes representan el 53\% del total de la matrícula (OCDE, 2009). Por otro lado, el estudio de Meneses, F., Rolando, R., Valenzuela, M. y Vega, M (2010) muestra que el 70\% de los estudiantes egresados el año 2005 de la educación particular pagada ingresa a la universidad al año siguiente de egreso, frente al $28 \%$ de los estudiantes de educación particular subvencionada y al 22\% de los egresados de la educación municipal y administrada por corporaciones. 
Por otro lado, la evidencia empírica respecto de la retención y deserción en la educación superior chilena muestra que los estudiantes de contextos vulnerables son los que presentan mayores dificultades para terminar sus estudios, debido a sus condiciones económicas y a los déficits de capital cultural heredado (González y Uribe, 2005; Canales y de los Ríos 2009; Meneses et al., 2010) Así también datos del CNED (2011) muestran que las experiencias de deserción se encuentran fuertemente diferenciadas según el tipo de institución, siendo las universidades las que logran mayores tasas de retención en comparación con los institutos profesionales y los centros de formación técnica. Estos antecedentes sugieren que, para los estudiantes, tanto las representaciones y significados de las carreras en las cuales se comprometen, como las políticas, prácticas y entornos socioinstitucionales pueden incidir significativamente en sus diferentes experiencias.

En este nuevo contexto, se reconocen al menos tres tensiones empíricas que enmarcan el problema de investigación: a) La emergencia de nuevas experiencias y exigencias para los jóvenes de escasos recursos que ingresan a la universidad; b) la desigual distribución de dichas experiencias debido a la segmentación del campo de la educación superior; y c) la emergencia de nuevos desafíos para las instituciones universitarias debido al ingreso de nuevos estratos sociales, antes excluidos de la educación superior.

Por otro lado, en la mayoría de los estudios revisados, nacionales e internacionales, se observa un énfasis en la universalización de la tesis bourdiana (Bourdieu y Passeron, 2003), la cual postula que el funcionamiento del sistema educativo se encuentra asociado a los habitus ${ }^{5}$ propios de las familias y estudiantes con altos capitales

4 Por ejemplo, el estudio de Meneses, F., Rolando, R., Valenzuela, M. y Vega, M (2010) da cuenta que en el año 2005, del total de egresados de la educación particular pagada que accedió entre los años 2006 y 2009 a la educación superior, un 82\% permaneció en ella. En contraste, menos del 50\% del resto de los jóvenes (provenientes de la educación particular subvencionada y municipal) que ingresaron a la educación superior continuaban en ella el año 2009

5 Se entiende por habitus a los esquemas generativos de obrar, pensar y sentir asociados a la posición social, lo que hace que las personas de un entorno social homogéneo tiendan a compartir estilos de vida parecidos. 
64 LA EXPERIENCIA DE ESTUDIANTES DE CONTEXTOS VULNERABLES EN DIFERENTES INSTITUCIONES DE EDUCACIÓN SUPERIOR UNIVERSITARIA (IESU): RESULTADOS DE INVESTIGACIÓN - D. Leyton, A. Vásquez, V. Fuenzalida

culturales (Canales y de los Ríos 2007, 2009; Meneses et al., 2010; González y Uribe, 2005; Forsyth y Furlong, 2003; Lehmann, 2007; 2009; Thomas y Quinn, 2007; Cooke, Barkham, Audin y Bradley, 2004; Koskinen, 2007; Stuber, 2011). Dicha perspectiva, si bien tiene una amplia aceptación basada en la evidencia empírica, obstaculiza el planteamiento de problemas orientados a reconocer y comparar las experiencias sociales y académicas en universidades con diferentes configuraciones socioinstitucionales, no necesariamente asociadas a los habitus de los estratos altos.

Así, conceptualizando las diferencias de cuatro instituciones de educación superior (IESU) en términos de "habitus institucionales", la investigación indagó comparativamente en las experiencias de integración social y académica de estudiantes de contextos vulnerables. Dentro de ese marco, se espera contribuir tanto a la visibilidad de esta problemática al momento de discutir políticas de inclusión en la educación superior, como a la comprensión de las experiencias sociales y académicas, continuando los incipientes estudios acerca de deserción/retención en Chile, pero observando las experiencias sin vincularlas a resultados externos.

\section{Discusión bibliográfica y perspectiva teórica}

\subsection{Las experiencias de integración social y académica}

Las experiencias de integración social y académica en la educación superior han sido estudiadas principalmente a partir de investigaciones acerca de deserción o retención, así como también a partir de estudios que abordan las experiencias de estudiantes de contextos vulnerables en diversos establecimientos educativos.

En dichos estudios los elementos centrales de la integración social se asocian con las posibilidades de relacionarse con sus compañeros, la intensidad y calidad de esas relaciones, la existencia de relaciones con sus profesores en espacios extraacadémicos y los niveles de participación en actividades extracurriculares. Por otro lado, las experiencias de integración académica se observan, principalmente, a partir del rendimiento académico, el desarrollo de habilidades de 
estudio, los niveles de satisfacción con el desarrollo intelectual y los aprendizajes adquiridos, la percepción que tienen los estudiantes de la calidad e interés por su aprendizaje por parte de los docentes y el compromiso que los estudiantes tienen con sus estudios (Pascarella y Terenzini, 1979; Pascarella, Duby e Iverson, 1983; Tinto, 1993; Thomas, 2002; Lizio, Wilson y Simons, 2002; Canales y de los Ríos 2007, 2009).

En Chile, y principalmente en los estudios respecto de la retención/deserción de los estudiantes en la educación superior, se evidencia que los factores más importantes que configuran las experiencias educacionales incompletas son las variables de origen social, tales como el capital económico (expresado en el ingreso forzado al mercado laboral o en la deserción por falta de recursos) y el capital cultural, heredado de las familias y el establecimiento de educación secundaria (Canales y de los Ríos 2007, 2009; González y Uribe 2005; Meneses et al., 2010; INJUV, 2006, 2009). Complementariamente, González y Uribe (2005) dan cuenta de otro factor: el sentimiento de desigualdad que tienen los estudiantes vulnerables frente a sus compañeros, percepción basada en la constatación del mayor capital cultural de los padres de estos últimos (es decir, que estudiaron profesiones universitarias) y en el establecimiento donde cursaron los estudios de Enseñanza Media (educación privada). En esta misma línea, el estudio de Canales y de los Ríos (2009, pp. 62-63) evidencia que "en instituciones de élite, los alumnos vulnerables se sienten especialmente distintos del resto de sus compañeros. El proceso de integración resulta arduo, porque los estudiantes desconocen la vida universitaria y sus requerimientos".

Por otro lado, Castillo y Cabezas (2010) en su estudio acerca de la trayectoria de los estudiantes que son primera generación ${ }^{6}$ al ingresar a la educación superior, dan cuenta de la importancia de elementos tales como el capital cultural, las expectativas familiares,

6 Es necesario tener en cuenta que el concepto de "estudiantes de primera generación" aborda realidades sociales más amplias y heterogéneas que las tratadas aquí bajo la noción de estudiantes vulnerables. No obstante, las experiencias y dificultades que reporta dicha investigación son de vital importancia para comprender las experiencias académicas de estudiantes vulnerables en sus tránsitos hacia la educación superior. 
66 LA EXPERIENCIA DE ESTUDIANTES DE CONTEXTOS VULNERABLES EN DIFERENTES INSTITUCIONES DE EDUCACIÓN SUPERIOR UNIVERSITARIA (IESU): RESULTADOS DE INVESTIGACIÓN - D. Leyton, A. Vásquez, V. Fuenzalida

las experiencias escolares previas y el desarrollo de proyectos educacionales postsecundarios dentro de las posibilidades de ingresar a la educación superior. Asimismo, los autores también evidencian la distancia entre la cultura estudiantil universitaria que demandarían las universidades y las disposiciones que tienen los jóvenes de primera generación para asumir esas demandas, debido a la influencia de sus condiciones sociales de origen familiar, local y escolar.

En sintonía con lo anterior, estudios internacionales de interés, principalmente desarrollados en el Reino Unido y Norteamérica, dan cuenta de que las diferencias de clase entre los estudiantes afectan las posibilidades de integración social y académica. En este sentido, los resultados han mostrado que los estudiantes de orígenes vulnerables que entran a instituciones de educación superior caracterizadas por una mayor proporción de estudiantes de clases media y alta se ven afectados en sus niveles de integración social, debido a la baja relación que logran establecer con sus profesores y compañeros, así como también por el sentimiento de dichos estudiantes de ser socialmente incompatibles, en términos de orígenes socioeconómicos y de estilos de vida, para relacionarse con otros estudiantes de la misma institución (Cooke, et al., 2004; Koskinen, 2007; Furlong y Cartmel, 2009).

Ahora bien, en relación con la integración académica, otras investigaciones dan cuenta de que los estudiantes vulnerables enfrentan dificultades en sus rendimientos académicos, en sus niveles de compromiso con sus carreras y con la institución (Lehmann, 2007, 2009; Thomas y Quinn, 2007).

Los estudios mencionados hasta aquí concuerdan en que las experiencias problemáticas que viven los estudiantes provenientes de contextos vulnerables al ingresar a la educación superior se explican por un desajuste entre los habitus individuales y la lógica institucional, de lo cual deriva la centralidad que tiene el "sentido de correspondencia" (sentirse ajustado al entorno social y académico) en el logro de la integración social y académica. No obstante, el uso del concepto de habitus institucional en la investigación educativa ha permitido problematizar dicha centralidad, asociándola con situaciones que perpetúan las experiencias de desigualdad. 


\subsection{El enfoque del habitus institucional en el estudio de las experiencias estudiantiles}

La utilización del habitus institucional en la investigación educativa tiene su origen hacia fines del siglo XX, en estudios que buscaron explorar la influencia que tenían las escuelas en las decisiones de los estudiantes respecto de la continuidad de sus estudios superiores (McDonough, 1997; Reay, 1998; Reay, David, Ball, 2001).

Desde esta perspectiva, el habitus institucional se constituye principalmente en la relación entre agencia y estructura comprendiéndose, en primera instancia, como la interacción entre la clase social de origen y el contexto socioinstitucional (McDonough, 1997; Ball, Davies, David y Reay, 2002).

En efecto, McDonough (1997) plantea que, junto con la clase social, el espacio educacional específico al cual asisten los estudiantes influye en el grado en que los jóvenes, con la misma posición social, proyectan diferentes futuros y se embarcan en trayectorias divergentes dentro de la educación superior. Por lo tanto, dicha configuración socioinstitucional puede producir diferentes experiencias y prácticas en agentes que comparten una misma posición de clase.

Siendo la configuración de la estructura de clase un elemento central en los estudios que han utilizado el concepto de habitus institucional en la investigación educativa, se pueden distinguir, al menos, dos perspectivas principales. La primera de ellas se puede denominar la perspectiva "organizacional", que tiene como referente principal las investigaciones realizadas por McDonough (1997), quien hace mayor énfasis en las dimensiones del habitus institucional propias de la cultura organizacional de la institución. Entre estas dimensiones la autora destaca los siguientes aspectos: la organización y los recursos del establecimiento; la estructura normativa (la misión y los valores en los cuales se funda); las preconcepciones acerca de los estudiantes y las expectativas que tienen para ellos; y, por último, la experticia y expectativas que tienen los agentes cuya función es el apoyo y la orientación de los estudiantes. 
68 LA EXPERIENCIA DE ESTUDIANTES DE CONTEXTOS VULNERABLES EN DIFERENTES INSTITUCIONES DE EDUCACIÓN SUPERIOR UNIVERSITARIA (IESU): RESULTADOS DE INVESTIGACIÓN - D. Leyton, A. Vásquez, V. Fuenzalida

La segunda perspectiva, por su parte, se puede denominar "culturalista" y enfatiza en las identidades y relaciones de clase que construyen los estudiantes con el ethos académico y de clase de la institución; esto último se asocia, principalmente, con los mecanismos de selección de estudiantes y la calidad y exigencia académica de las instituciones educativas. Dentro de esta posición se encuentran los estudios llevados adelante por Reay et al. (2001; 2009; 2010) e Ingram (2009). Entre las principales dimensiones utilizadas por estas investigaciones que estructuran el habitus institucional de las organizaciones educativas se encuentran los siguientes aspectos: los mecanismos y niveles de selección de los estudiantes, sus características socioeconómicas y culturales, el ethos o nivel académico de la institución, la oferta curricular y, finalmente, las políticas de apoyo a los estudiantes de la organización.

Asociado a esta última perspectiva, existen investigaciones que dan cuenta de algunos elementos centrales de las experiencias sociales y académicas relacionadas con el habitus institucional. En este sentido, Crozier, G., Reay, D., Clayton, J., Colliander, L. \& Grinstead, J. (2008) y Reay, et al., (2010) destacan las identidades que desarrollan los sujetos en tanto estudiantes. Dichas identidades dependerían, fuertemente, del entorno sociocultural e institucional en el cual se encuentren cursando sus estudios y no tanto del sentido de pertenencia o comodidad que puedan sentir en dichos espacios. En este sentido, las identidades académicas fuertes dependerán del grado de exigencia que es percibido en el ambiente universitario y que ello, además, les demande un alto nivel de inversión de tiempo en actividades universitarias. Por otro lado, los autores plantean que los estudiantes que provienen de la clase trabajadora, que se encuentran en universidades orientadas a estratos bajos y que cuentan con una cultura académica menos exigente, en general, se sienten cómodos e identificados con dicho entorno, pero desarrollan identidades académicas frágiles con una significativa falta de confianza en sus capacidades. Dicho contexto socioinstitucional, por su parte, fuerza a los estudiantes vulnerables con mayores disposiciones hacia el aprendizaje y los estudios a suprimir sus habitus académicos y a aparentar un bajo compromiso con sus estudios, como estrategia para poder integrarse en dicha cultura estudiantil. 
También se encuentran estudios que destacan el efecto de las diversas configuraciones de la estructura de clase dentro de las organizaciones educativas en las experiencias sociales y académicas de los estudiantes. En esta línea, Osborne y Brennan (2008) y Thrupp (1999) plantean que la mixtura social dentro de los establecimientos educacionales (de educación superior en el primero y de educación secundaria, en el segundo) permite a los estudiantes de contextos vulnerables vivenciar experiencias sociales y académicas más enriquecedoras, puesto que los estudiantes de dichas clases sociales que se encuentran en entornos con altos grados de mixtura socioeconómica se encontrarían expuestos a los beneficios de entornos y expresiones culturales diferentes. Este último autor enfatiza también en que la composición socioeconómica y cultural de los estudiantes afecta las prácticas de las instituciones educativas. De esta forma, los establecimientos desarrollan procesos y prácticas que reflejarían la composición sociocultural de los estudiantes.

Ante la centralidad de la estructura de clase como dimensión constitutiva del habitus institucional, la propuesta de Bernstein (1975) adquiere suma relevancia cuando plantea que "aspectos constitutivos de lo que sería una situación de clase generan formas particulares de comunicación que, a su vez, modelan orientaciones intelectuales y sensibilidades" (Cox, 1987, p. 12). En este sentido, situaciones de clases homogéneas o con mayores grados de heterogeneidad podrían desarrollar disposiciones académicas y "sentidos del juego" diferenciados, lo que permitiría orientar dichas disposiciones hacia las cuestiones definidas como "importantes" dentro del espacio universitario ${ }^{7}$.

7 La generación de diferentes disposiciones, asociadas a disímiles situaciones de clase, está relacionada con los denominados "códigos restringidos" y "códigos elaborados". Los códigos restringidos se caracterizan por el uso de un lenguaje simple, con escasa elaboración abstracta, que permite trascender el contexto experiencial de origen ligado a los vínculos establecidos en la localidad o familia. Por su parte, los códigos elaborados hacen referencia al uso de frases y gramática más complejas, cuya estructura se encuentra fundada en una disposición a buscar una mayor generalidad. El uso del código restringido sería característico de los códigos culturales de las clases trabajadoras, en tanto que el uso de los códigos elaborados serían propios de los códigos culturales de las clases medias y altas. Para una mayor profundización véase Bernstein (1975). 
70 LA EXPERIENCIA DE ESTUDIANTES DE CONTEXTOS VULNERABLES EN DIFERENTES INSTITUCIONES DE EDUCACIÓN SUPERIOR UNIVERSITARIA (IESU): RESULTADOS DE INVESTIGACIÓN - D. Leyton, A. Vásquez, V. Fuenzalida

Si bien el foco principal de esta investigación se encuentra sustentado más en la perspectiva culturalista, también se rescatan elementos de la visión organizacional, como, por ejemplo, la misión y los valores que orientan a las universidades, el rol de los tutores o monitores en la transición hacia la educación superior de los estudiantes vulnerables y, por último, la importancia de las instalaciones dispuestas tanto para la práctica de actividades extraprogramáticas como para las de estudio.

\section{Metodología de la presente investigación}

En esta investigación se desarrollaron 29 entrevistas semiestructuradas a estudiantes de contextos vulnerables pertenecientes a cuatro diferentes instituciones de educación superior del país ${ }^{8}$. A través de estas se buscó profundizar en las experiencias de los alumnos desde sus propios esquemas de observación, valoración y acción (Canales, 2006), situándolos en un contexto significativo determinado. Dicho contexto es, en este caso, el de las instituciones de educación superior, las cuales, metodológicamente, fueron definidas como casos diferenciados de acuerdo con las características centrales que posibilitan una estructuración inicial sus "habitus institucionales".

Para la selección de las cuatro universidades se privilegió el que ellas se diferenciaran estructuralmente en, al menos, las siguientes dimensiones: la composición socioeconómica de los estudiantes (según el porcentaje de estudiantes por tipo de establecimiento de procedencia); el nivel de selectividad académica (de acuerdo con el porcentaje de estudiantes con puntajes en la PSU mayor a 600 puntos); el nivel académico (en función del tamaño del cuerpo docente, la jornada académica, el grado académico de ellos y la infraestructura dispuesta para las prácticas de estudio); y, por último, la ausencia o presencia de políticas y prácticas que promuevan la integración social y académica de estudiantes de contextos vulnerables. En forma particular se seleccionaron dos universidades que implementaran

8 Una vez comenzado el trabajo de campo se incorporaron, además, observaciones etnográficas realizadas en las universidades al momento de la búsqueda de los estudiantes que serían entrevistados. 
programas propedéuticos. La centralidad de estos programas se explica porque constituyen uno de los elementos que se focaliza, específicamente, en estudiantes de contextos vulnerables y que, a su vez, presenta mayores grados de sistematicidad ${ }^{9}$.

Los estudiantes entrevistados que participaron en el estudio se distribuyeron equitativamente entre hombres y mujeres, tienen entre 18 y 30 años y se diferenciaron también según si se encontraban en los dos primeros años de estudio, o bien en los últimos años ${ }^{10}$. Es posible observar que la totalidad de ellos reside en comunas de bajos recursos.

En cuanto al establecimiento de procedencia, casi todos los entrevistados terminaron la educación media en establecimientos municipales, o bien particulares subvencionados de estatus socioeconómico bajo, en su mayoría con educación técnica ${ }^{11}$.

De acuerdo con lo declarado por los entrevistados, la mayoría tiene un ingreso familiar igual o inferior a 350.000 pesos, presentando un promedio de ingresos de 377.000 pesos.

Respecto del nivel educativo de los padres ${ }^{12}$, la mayoría de ellos tiene un nivel de educación igual o inferior a enseñanza media completa, siendo menor en general la educación de las madres ${ }^{13}$.

Complementariamente con lo anterior, el tipo de trabajo

9 También se tomó en cuenta el número y tipo de becas que cada una de las universidades otorga a sus estudiantes. Se privilegió tanto al programa propedéutico como a las becas, atendiendo a tres criterios: las políticas orientadas a reconocer el mérito académico; aquellas orientadas a reconocer las barreras de inclusión económica; y, por último, aquellas orientadas a reconocer las barreras de integración social y académica.

10 La diferencia entre el periodo de estudio en el cual se encuentren puede ser relevante, ya que existe evidencia de que los primeros años son los más difíciles para los estudiantes de estratos bajos.

11 Si bien debido al carácter exploratorio de la investigación no se buscó seleccionar a los estudiantes de acuerdo con carreras específicas, se aprecia que la mayoría de ellos se encuentra realizando estudios en carreras de orientación humanista y/o cercanas a la intervención, como por ejemplo, Bachillerato en Humanidades y Ciencias Sociales, Pedagogía y Trabajo Social. A partir de este criterio metodológico es necesario advertir también que en esta instancia no se ha realizado un análisis por campo disciplinar o carreras.

12 O personas responsables, en caso de ausencia de ellos.

13 En seis casos las madres no terminaron la enseñanza básica y en tres casos las madres no terminaron la enseñanza media. 
que desempeñan los padres se encuentra diferenciado por género. Así, la mayoría de las madres se dedica a labores domésticas, en tanto que aquellas que desarrollan trabajos remunerados realizan actividades no calificadas, principalmente como asesoras del hogar, telefonistas, o bien trabajos esporádicos. Por otro lado, la mayoría de los padres se desempeña en trabajos no calificados (guardias, obreros de la construcción sin calificación, peones agropecuarios, etc.), o bien en labores manuales de mayor calificación (choferes de vehículos, operadores de productos farmacéuticos, electricistas de baja calificación o carniceros, entre otros) $)^{14}$.

La búsqueda de los estudiantes, en tanto, se orientó a través de diversos mecanismos, tales como la información entregada por las universidades y, cuando esto fue posible, por medio de su búsqueda directa en los espacios universitarios o también aprovechando el "boca en boca". Una vez seleccionados los potenciales estudiantes por entrevistar, se procedió a contactarlos mediante llamados telefónicos y/o correo electrónico, con el fin de informales acerca del carácter y objetivo de la investigación y obtener el consentimiento libre de ellos para ser entrevistados ${ }^{15}$.

Finalmente, las entrevistas realizadas se transcribieron e incorporaron al software QSR Nvivo 8. Su posterior análisis se realizó a partir de la construcción de macrocategorías predeterminadas, para luego desarrollar una codificación abierta en cada una de ellas.

\section{Algunos rasgos del habitus institucional de las universidades}

Las cuatro universidades seleccionadas fueron diferenciadas teniendo en cuenta los siguientes aspectos: la importancia de las políticas de admisión expresadas en las características sociales y académicas

14 Todas las ocupaciones de los padres o personas responsables de sus hogares se clasificaron de acuerdo con los grupos de ocupaciones establecidos por la clasificación internacional de ocupaciones CIUO 88 www.ilo.org/public/spanish/bureau/stat/isco/isco88/

15 El equipo de investigación se comprometió con los entrevistados a mantener el anonimato, tanto de sus identidades, como de la universidad en la cual se encuentran cursando sus estudios. 
de sus estudiantes y en la configuración del habitus institucional (Ingram, 2009); la descripción de las políticas y programas de apoyo a estudiantes vulnerables; $y$, por último, la calidad de su planta docente y la misión institucional. Lo anterior permitió acuñar los siguientes nombres para los distintos tipos de instituciones: universidad académica pluriclasista, universidad no-académica pluriclasista, universidad de élite y universidad de estratos bajos.

La universidad académica pluriclasista se caracteriza por tener cerca de un 30\% de estudiantes con puntajes mayores o iguales a 600 puntos en la $\mathrm{PSU}^{16}$. No obstante, logra romper, en alguna medida, la asociación entre selectividad académica y social, puesto que presenta una composición de clase más o menos heterogénea ${ }^{17}$, lo que a su vez se ve reforzada por la existencia de algunas becas que reconocen las barreras económicas de los estudiantes y por la implementación del programa propedéutico (iniciativa orientada a promover la integración de estudiantes provenientes de contextos vulnerables, considerados talentosos en virtud de sus logros académicos en la secundaria). Sumado a lo anterior, esta institución mantiene un alto ethos académico, reflejado no solo en la selectividad académica, sino también en un discurso oficial que lo promueve y en la relativa alta calidad de sus docentes.

La universidad no académica pluriclasista es la que presenta la mayor heterogeneidad social de sus estudiantes ${ }^{18}$, lo que se refleja en una política de admisión que se complementa con un sistema de becas económicas y sociales, además del programa propedéutico en el cual participan más estudiantes que en la universidad anterior. En efecto, en los últimos años han entrado a esta universidad cerca de 200 estudiantes cada año gracias a su programa. Sin embargo, dicha universidad no logra configurar una cultura académica fuerte, teniendo menos del 10\% de docentes con grado de doctor y un porcentaje similar de docentes a tiempo completo, lo cual también

$16 \mathrm{PSU}=$ Prueba de Selección Universitaria.

17 Un 24\% proviene de la educación municipal; 52\% de la educación particular subvencionada; y un $24 \%$ de la educación particular pagada (CNED, 2010).

18 Según el origen socioescolar de sus estudiantes solo el 11\% proviene de la educación particular pagada y un 63\% de la educación particular subvencionada (CNED, 2010). 
74 LA EXPERIENCIA DE ESTUDIANTES DE CONTEXTOS VULNERABLES EN DIFERENTES INSTITUCIONES DE EDUCACIÓN SUPERIOR UNIVERSITARIA (IESU): RESULTADOS DE INVESTIGACIÓN - D. Leyton, A. Vásquez, V. Fuenzalida

se refleja en la percepción de los estudiantes entrevistados.

La universidad de élite, a través de su política de selección, refleja una orientación exclusiva hacia los estudiantes procedentes de la educación particular pagada. Así también, la orientación de sus ayudas estudiantiles solo reconoce el rendimiento académico de sus estudiantes en la universidad. Por otro lado, su misión institucional busca promover en sus estudiantes disposiciones de acción orientadas al liderazgo, emprendimiento y eficacia, cuestiones asociadas más a la inserción profesional que a la excelencia académica propiamente tal. Este tipo de universidad se destaca igualmente por la calidad de su planta docente, en donde más del $40 \%$ de los educadores posee estudios de postgrado y, además, corresponde, dentro de la categoría propuesta, a la segunda institución con mayor cantidad de docentes contratados después de la universidad académica pluriclasista.

Por último, la universidad de estratos bajos tiene una política de admisión no selectiva y no exige un puntaje mínimo de ingreso en la PSU. Esto se encuentra asociado al perfil socioeconómico de sus estudiantes, los cuales provienen en un $65 \%$ de la educación municipal y solo un 3\%, de la educación particular pagada. Ahora bien, la incorporación de una gran proporción de estudiantes de orígenes vulnerables se debe más a la ausencia de selectividad académica (mediante PSU u otros mecanismos) que a la presencia de becas o programas de integración social y académica, ya que estos últimos no se han implementado en dicha universidad ${ }^{19}$. Por otro lado, en esta universidad se presenta la situación docente más deficitaria dentro de las cuatro universidades seleccionadas para la investigación: menos de un $5 \%$ de sus profesores se encuentra contratado y menos del 18\% de ellos posee estudios de postgrado. Por último, la misión de dicha universidad se expresa en la inserción de sus estudiantes en el mercado laboral, por lo que se encuentra, respecto de este punto, más cercana a la posición de la universidad de élite que a las otras dos universidades pluriclasistas.

19 Es necesario considerar también que dicha universidad no se encuentra acreditada por la Comisión Nacional de Acreditación, CNA, por lo que sus estudiantes se encuentran imposibilitados de optar al sistema de créditos o becas otorgados por el Estado de Chile. 


\section{Resultados}

\subsection{Las experiencias de desclasamiento ascendente en la transición hacia las universidades}

En su mayoría, los estudiantes entrevistados reconocen la precariedad de su formación en la etapa escolar. Dicha percepción se reconoce con más fuerza luego de ingresar a la educación superior, ya que es ahí donde emerge, para la mayoría, la diferencia social y académica entre la experiencia escolar y la experiencia universitaria, brecha que se ve expresada en un sentimiento de desventaja frente al nivel de acumulación de capital cultural, económico y social que poseen sus compañeros.

En mi colegio iba a clases y apenas escribía, era más que nada tomar atención, pero aun así tenía muy buenas notas, no fallaba en eso. Encontraba que el colegio era fácil porque los profesores no eran muy exigentes, la materia era casi siempre lo mismo, entonces era muy básico ( $1^{\text {er }}$ año, universidad no-académica pluriclasista).

Al observar las relaciones sociales que establecieron en la escuela y compararlas con el espacio social propio de sus universidades, se observa una experiencia de desclasamiento ascendente $e^{20}$ que implica un distanciamiento con su origen social. En la universidad de élite el distanciamiento se expresa a través de una negación violenta de pertenencia con dicho entorno y en la caracterización de sus compañeros escolares como resentidos y "flaites"21.

En $3^{\circ}$ dije "Estoy loca, son puros resentidos sociales, ya no me junto con nadie más" ( $2^{\circ}$ año, universidad de élite).

20 Si bien la mayoría de las investigaciones sobre desclasamiento tematizan las experiencias de movilidad descendente (Jiménez, 2011) o el temor al desclasamiento en tanto degradación de su posición actual o inconsistencia de posición (Araujo y Martucceli, 2011), es importante también considerar las tensiones y conflictos que se presentan ante las experiencias de desclasamiento producto de procesos de movilidad ascendente, sobre todo teniendo en cuenta tanto las resistencias de los individuos y de sus familias ante dicha posibilidad, como los propios conflictos de identidad que surgen en ese proceso.

21 En Chile corresponde a un adjetivo calificativo despectivo, utilizado para referirse a ciertas personas de baja condición social. 
76 LA EXPERIENCIA DE ESTUDIANTES DE CONTEXTOS VULNERABLES EN DIFERENTES INSTITUCIONES DE EDUCACIÓN SUPERIOR UNIVERSITARIA (IESU): RESULTADOS DE INVESTIGACIÓN - D. Leyton, A. Vásquez, V. Fuenzalida

Igual en mi colegio eran puros flaites, la mayoría era flaites, que era en Maipú ( $1^{\text {er }}$ año, universidad de élite).

Este discurso clasista se puede comprender como una estrategia orientada a superar la distancia significativa que existe entre los entrevistados y los estudiantes de estratos altos de dicha universidad. En un espacio de élite socioeconómica los estudiantes de orígenes vulnerables se ven forzados a desclasarse y negar su origen como un mecanismo de integración social. En efecto, a partir de las observaciones de campo realizadas, se pudo apreciar cómo en dicha universidad el proceder de escuelas públicas es algo negado por los estudiantes, con lo cual están coartando su posibilidad de reconocerse en dicho origen socioescolar. En este sentido, si acceder a la vida universitaria "supone un proceso de adquisición y adaptación a nuevos códigos culturales y simbólicos" (Canales y de los Ríos, 2009, p. 63), dicho proceso, en este contexto de clase, supone para los estudiantes de orígenes vulnerables la adquisición de herramientas de negación y ocultación de su historia social. Es decir, en un habitus institucional que impugna la identidad social de los estudiantes de orígenes vulnerables, estos se verían inclinados a renegar de sus contextos de procedencia y asumir de manera dóxica los presupuestos que permiten la integración social.

En las otras tres universidades, la forma dominante de expresar el desclasamiento es, en general, a través de la conciencia de haber desarrollado trayectorias educativas disímiles no esperadas (sí deseadas), lo que los lleva a vivir una distancia con su entorno escolar y barrial de origen, porque se reconocen como casos excepcionales en comparación con las transiciones directas al trabajo o de desempleo que experimentan sus compañeros de la educación secundaria.

Es medio irregular juntarme con ellos, porque igual ellos tomaron el camino que yo iba a tomar, que es de titularse y trabajar ( $1^{\text {er }}$ año, universidad académica pluriclasista).

La experiencia de desclasamiento y el correlativo distanciamiento de sus orígenes sociales, evidencia una tensión ante la posibilidad de articular el mundo social de origen con el mundo universitario, porque se asume dicha opción como riesgosa e incompatible. 
Toda movilidad ascendente trae consigo un posible desclasamiento objetivo, por ello las formas de vivirlo y las estrategias utilizadas para abordarlo, por parte de los estudiantes entrevistados, presentan un conflicto que marca la entrada a la universidad, el cual puede ser más o menos violento, dependiendo de las características sociales y culturales que definen a una universidad, así como también de la existencia de políticas que reconozcan dicho conflicto.

Es que mis amigos de la casa, la mayoría ya terminó de estudiar, está trabajando, tienen otra forma de relacionarse con la gente, yo creo que si los junto puede haber más de un problema, por eso no me he arriesgado a eso ( $1^{\text {er }}$ año, universidad no-académica pluriclasista).

\subsection{Las percepciones respecto del entorno social: sentimientos de desigualdad, oportunidades de las distancias y la reproducción en la homogeneidad}

Las percepciones acerca del entorno social se estructuran, en primer lugar, a partir de las diferencias de clase percibidas por los entrevistados entre ellos mismos y sus compañeros, diferencias que se tornan evidentes al comparar las características de los estudiantes universitarios con las de sus compañeros en la secundaria; y, en segundo lugar, a partir de la valoración que hacen los entrevistados de dicho entorno.

El sentimiento de distancia entre los entrevistados y los compañeros universitarios se observa con mayor fuerza en la universidad de élite y la universidad académica pluriclasista, las cuales comparativamente presentan una mayor proporción de estudiantes de estratos altos. La distancia percibida expresaría el sentimiento de desigualdad existente en dichos estudiantes (González, L. Uribe, D. y González, S. 2005). Estos altos grados de inadecuación se vivencian con mayor intensidad en los estudiantes de primer año, los cuales se expresan en sentimientos de temor o intimidación, tanto en ellos como en sus familias (Lehmann, 2009).

Tengo muchos compañeros que el papá es ingeniero, otro que la mamá era Decana. Y uno ¡uh! "No, mi papá hace aseo. No, mi papá es guardia", como que 
78 LA EXPERIENCIA DE ESTUDIANTES DE CONTEXTOS VULNERABLES EN DIFERENTES INSTITUCIONES DE EDUCACIÓN SUPERIOR UNIVERSITARIA (IESU): RESULTADOS DE INVESTIGACIÓN - D. Leyton, A. Vásquez, V. Fuenzalida

siempre los trabajos son humildes ( $1^{\text {er }}$ año, universidad académica pluriclasista).

Creo que mi mamá se asustó un poco porque yo venía de un colegio de menos recursos... Fue terrible llegar a la universidad y que (tomando en cuenta que) la gente que está acá es más rica y tiene más posibilidades, a lo mejor a uno lo pueden discriminar $\left(2^{\circ}\right.$ año, universidad académica pluriclasista).

No obstante, los resultados de la investigación indican que en las dos universidades pluriclasistas, el reconocimiento de la desventaja social no impide apreciar la oportunidad de socialización bajo otras lógicas. En efecto, dichos estudiantes valoran positivamente la experiencia de encontrarse en un ambiente universitario caracterizado tanto por los altos niveles de capital cultural, como por su diversidad expresiva. A su vez, aprecian la posibilidad de establecer relaciones sociales que les permitan incorporar mayores grados de racionalidad en sus percepciones de mundo y también valoran la existencia de nuevos y diferentes puntos de vista, los cuales remiten a experiencias asociadas con mayores grados de tolerancia y libertad.

Son como gente que no se preocupa tanto de eso, no hay tanta discriminación, hay como más libre pensamiento, como más libertad de actuar... Es gente súper abierta de mente, gente que comprende otras cosas, que conoce otros temas... dan ganas de aprender de ellos $\left(1^{\circ}\right.$ año, universidad académica pluriclasista).

Es rico estar en la universidad porque tienes otros puntos de vista ( $1^{\text {er }}$ año, universidad no-académica pluriclasista).

Por su parte, los estudiantes de la universidad de estratos bajos, si bien reconocen la homogeneidad y familiaridad socioeconómica entre ellos y sus compañeros, esta identificación no opera necesariamente como facilitador de la experiencia de integración social, ya que no existe una alta valoración de las relaciones sociales entre los estudiantes. Más aún, en este espacio homogéneo la experiencia cultural diversa es menos tolerable y se perciben menos espacios de aceptación de las diversas manifestaciones expresivas, 
lo cual fuerza a adoptar las maneras socialmente aceptadas como estrategia de integración social.

Eso (integrarme con mis compañeros) a mí me costó un poco. Igual al principio lo sentí... era discriminado en la "U" porque andaba con mi gorro para el lado y veía puros hippies con su morral... Yo sentí que tenía que cambiar, que ganar aceptación ( $3^{\text {er }}$ año, universidad de estratos bajos).

\subsection{La participación en espacios extraacadémicos y la} experiencia de las relaciones sociales

Si bien las percepciones del entorno social en las universidades pluriclasistas dan cuenta de las posibilidades de tener una experiencia social más democrática, la que al mismo tiempo permite amortiguar el sentimiento de desigualdad, dicha estructura no asegura automáticamente una experiencia de alta integración social. En efecto, la mayoría de los entrevistados experimentan algunos obstáculos que disminuyen sus posibilidades de integración social en sus universidades, lo cual está asociado a los bajos niveles de participación en actividades extracurriculares y a las escasas relaciones sociales. Dichos obstáculos se expresan de forma diferente según el tipo de universidad y habitus institucional que las distingue.

Por ejemplo, los entrevistados de las universidades pluriclasistas tienen bajos niveles de participación tanto en actividades organizadas por los estudiantes como en aquellas extracurriculares ofertadas por sus universidades. Si bien ambos espacios de participación son valorados por los entrevistados como importantes para su interacción y compromiso con la institución, se reportan pocos casos de participación, principalmente entre los estudiantes que cursan sus primeros años de estudio.

El segundo obstáculo común que enfrenta la mayoría de los entrevistados de ambas universidades, en especial quienes se encuentran en los primeros años de estudio, se expresa en los grados de clausura social que les impide ampliar las redes de sociabilidad más allá de los compañeros que comparten su misma situación social de 
80 LA EXPERIENCIA DE ESTUDIANTES DE CONTEXTOS VULNERABLES EN DIFERENTES INSTITUCIONES DE EDUCACIÓN SUPERIOR UNIVERSITARIA (IESU): RESULTADOS DE INVESTIGACIÓN - D. Leyton, A. Vásquez, V. Fuenzalida

origen, lo cual disminuye las posibilidades de sostener intercambios sociales más fluidos y frecuentes con estudiantes herederos de otros capitales.

Al principio estábamos todos juntos como niñitos de jardín, los del propedéutico estábamos todos juntos, nos juntábamos en los recreos, entonces como que fue chocante, como que uno pensaba que tenía que sonar el timbre y todos decían " $\mathrm{O}$ Oye chiquillas es la hora!" $\left(2^{\circ}\right.$ año, universidad académica pluriclasista).

De partida las clases... fuera de las clases nos juntamos con casi todos los del programa de Bachillerato, andamos casi todos juntos, nos juntamos en el patio ahí a conversar, a echar la talla un rato y cuando hay que estudiar, me voy a estudiar ( $1^{\text {er }}$ año, universidad no-académica pluriclasista).

Esta situación puede actuar como cortapisa tanto para la retención como para la elección de una carrera (particularmente en el caso de los estudiantes de Bachillerato), debido a que muchos de estos alumnos, luego de sus primeros años, deben trazar sus propios caminos educativos, lo cual los fuerza a elegir carreras similares, para no distanciarse de sus compañeros cercanos, o bien, se dificultarán las experiencias sociales de aquellos que seleccionen otros campos disciplinares. En efecto, se reportan experiencias en las cuales estudiantes de orígenes vulnerables que han seleccionado otras carreras, han desertado o solicitado el cambio a las carreras donde se encuentran sus compañeros anteriores.

Yo creo que los otros niños todavía siguen como en el grupito que están en la misma carrera y son como todos iguales... uno empezó con Ingeniería Comercial y se cambió a Educación, después otro estaba en Ciencias Políticas y también se cambió a Educación y como que todos están en Educación y son todos los del propedéutico ( $2^{\circ}$ año, universidad académica pluriclasista).

Sin embargo, muchos han logrado configurar importantes relaciones de amistad, las cuales se perciben como fundamentales no 
solo para enfrentar las demandas sociales y académicas. En particular, los estudiantes beneficiarios del programa propedéutico reconocen en dicha política institucional un espacio propicio para la configuración de lazos sociales fuertes, desarrollo de habilidades sociales y apoyo psicológico.

Yo creo que sí son importantes (las relaciones de amistad en la universidad) porque uno no se siente tan solo en la universidad y no es solamente en el estudio, porque igual es para recrearse... al final que uno no tiene esa motivación para venir " $¡ O h$ ! Voy a ir a la "U”, a estudiar, qué lata”. En cambio, así voy a ver a los chiquillos hoy día, entonces así en las ventanas uno no está solo porque hay tanta gente en el patio que uno no se siente mal $\left(2^{\circ}\right.$ año, universidad académica pluriclasista).

Te ofrecían psicólogos... y ahora te dan acceso a diferentes becas, no sé, te ponen ayudantes y siempre te están preguntando todo el tiempo. En el propedéutico había una clase de desarrollo personal, te dicen que no puedes estar callado en una universidad, que tienes que saber tener voz, hablar y hacían hablar a la gente de todo, te daba vergüenza, pero funcionaba $\left(1^{\text {er }}\right.$ año, universidad no-académica pluriclasista).

Los estudiantes entrevistados pertenecientes a la universidad de élite, por su parte, crean vínculos sociales débiles, con pocas relaciones de amistad y un temor al aislamiento social. Dicho sentimiento ha forzado a algunos de ellos a desarrollar estrategias de instrumentalización de las relaciones sociales a través de favores, con lo cual evitan enfrentar los desafíos académicos de forma solitaria.

Para no quedarme sola para el otro ramo les tuve que hacer (a mis compañeros) clases una semana entera para una prueba ( $4^{\circ}$ año, universidad de élite).

Bueno, al final igual tengo que sociabilizar con la gente, porque uno viene a estudiar, pero tampoco viene a estar solo, porque después igual vas a tener que trabajar en equipo y si tú no sabes trabajar en equipo... yo trato 
82 LA EXPERIENCIA DE ESTUDIANTES DE CONTEXTOS VULNERABLES EN DIFERENTES INSTITUCIONES DE EDUCACIÓN SUPERIOR UNIVERSITARIA (IESU): RESULTADOS DE INVESTIGACIÓN - D. Leyton, A. Vásquez, V. Fuenzalida

de acercarme igual con los que yo trabajo ( $3^{\circ}$ año, universidad de élite).

Por otro lado, los estudiantes entrevistados de esta universidad, si bien reconocen una amplia oferta de actividades deportivas y recreativas, muchas de ellas chocan con sus habitus de origen, debido a que se encuentran asociadas a disposiciones más propias de estudiantes de clases altas, evidenciando el ethos inadecuado que caracteriza en este ámbito a dicha universidad (González y Uribe, 2005; Donoso y Cansino, 2007). Esto se refleja en la siguiente cita en la cual se expresa de forma sarcástica la distancia de clase y el desconocimiento entre los habitus individuales de los estudiantes de orígenes vulnerables y las disposiciones institucionales que ofrece esta universidad para el desarrollo de las actividades extraacadémicas:

(Hay) Pesca con mosca. Entonces estamos hablando de una cuestión que yo no estaba acostumbrada... digo "Ah qué rico, polo, los caballitos, equitación”, pero tampoco nunca averigüé, siempre me quedé con esa bala pasada de averiguar: ¿Necesito un caballo? ( $5^{\circ}$ año, universidad de élite).

Las experiencias sociales de los estudiantes de la universidad de estratos bajos, en tanto, se caracterizan principalmente por la baja participación en actividades extraacadémicas debido a tres factores: la inexistencia de espacios institucionales para ello, la ausencia de una cultura estudiantil que promueva o demande, organizadamente, dichos espacios y la fragilidad de las relaciones sociales de amistad que ellos establecen. Esto último también se asocia al tipo de trayectoria educativo-laboral dominante de estos estudiantes, en la que se combina, en un mismo periodo, el trabajo con las actividades académicas, lo que impide desplegar una experiencia focalizada en ocupar más tiempo en la vida social y académica universitaria.

Lo anterior se corresponde con los resultados de investigaciones recientes en el Reino Unido, las cuales indican que las universidades que no contemplan dispositivos institucionales que fuercen a los estudiantes a pasar gran parte de su tiempo "viviendo la vida universitaria" genera que las posibilidades de tener experiencias 
sociales significativas disminuyan. Por otro lado, aquellas universidades más prestigiosas serían las que otorgan menos posibilidades de compatibilizar estudios y trabajo y, por el contrario, aquellas orientadas a estudiantes menos aventajados, las instituciones que sí facilitan dicha articulación, afectando desigualmente las posibilidades de acceso y las experiencias educacionales (Metcalf, 2003; Reay, D. Crozier, G. y Clayton, J. 2010). En este sentido, se destaca la práctica que tiene la universidad no-académica pluriclasista, que ofrece empleo dentro de la propia universidad a aquellos estudiantes del programa propedéutico que corran el riesgo de tener que incorporarse al mercado laboral por razones económicas.

Por último, tanto en las universidades de élite como en aquellas pluriclasistas, los obstáculos para la integración social también se expresan en la oposición entre la representación del espacio universitario como un espacio de relaciones sociales y la representación de la universidad como un espacio académico; es decir, como un instrumento primordial de adquisición de conocimientos a través de prácticas de estudio y aprendizaje. Muchos de los entrevistados evidenciaron una dificultad de trascender la visión de la universidad más allá de lo propiamente académico, incluso percibiendo las prácticas de sociabilidad como una pérdida de tiempo.

En este momento jestudio, estudio, estudio! por la razón de que primero quiero reconocer el territorio bien, que me vaya bien... creo que en la carrera de mi conducencia ahí podría hacer algo ( ${ }^{\text {er }}$ año, universidad académica pluriclasista).

5.4. La experiencia de ajuste académico: transformaciones y reproducciones de las prácticas académicas en la transición hacia las universidades

Entendiendo la experiencia de ajuste como la adecuación de sus prácticas académicas (incorporadas en la etapa escolar) a las exigencias de la educación universitaria, los entrevistados de todas las universidades manifiestan la necesidad de dicha adecuación debido a la precariedad formativa en la escuela. Así, las deficiencias formativas 
84 LA EXPERIENCIA DE ESTUDIANTES DE CONTEXTOS VULNERABLES EN DIFERENTES INSTITUCIONES DE EDUCACIÓN SUPERIOR UNIVERSITARIA (IESU): RESULTADOS DE INVESTIGACIÓN - D. Leyton, A. Vásquez, V. Fuenzalida

adquiridas durante la etapa escolar actúan como un obstáculo al momento de enfrentar con éxito las demandas académicas de la institución.

Sin embargo, tal experiencia se ha tornado más o menos intensa de acuerdo con el tipo de institución en la cual los entrevistados desarrollan sus estudios. En el caso de los estudiantes de la universidad académica pluriclasista, caracterizada por una alta exigencia académica, la experiencia de ajuste significó un proceso intenso de adaptación y transformación de sus hábitos de estudio previamente adquiridos. Asimismo, los estudiantes que son beneficiarios del programa propedéutico evidencian que, a través de él y de las propias carreras, han logrado una experiencia de ajuste que les permite responder a las demandas académicas. En efecto, la política de inclusión a través del programa propedéutico interviene como un dispositivo de socialización e incorporación de herramientas de conocimiento teórico-prácticas necesarias en la universidad, con lo cual se suaviza el encuentro entre las disposiciones individuales (asociadas a bajos capitales culturales) y el espacio institucional cercano al manejo de códigos de la "alta cultura" reconocidos por las élites.

Me pasan hartas herramientas tanto en el propedéutico como en el Bachillerato.... nos enseñaban hábitos de estudio, tienes que leer, tienes que identificar la idea central de tal texto, formas de cita APA, cosas así. Inmediatamente nos dijeron: ¡tienes que estudiar en tal lugar, pecado leer en el metro o en la micro! ( $1^{\circ}$ año, universidad académica pluriclasista)

Por el contrario, en la universidad de estratos bajos no existe un ethos de alta exigencia orientado a promover una experiencia académica signada por la ruptura o transformación de las disposiciones académicas previas. Esta deficiencia permite una experiencia de ajuste más confortable para los estudiantes, pero a través de mayores grados de correspondencia con las disposiciones adquiridas en la etapa escolar. Aun cuando se reportan experiencias que revelan la exigencia de ajuste, estas no son tan enfáticas como en las experiencias de los entrevistados de las otras universidades. Aquí, los mayores grados 
de comodidad y sentimientos de correspondencia con las exigencias académicas se ponen al servicio de la reproducción.

Estudio menos, ya casi ni estudio... por eso te digo, si la materia no la entiendo o es más difícil, ahí estudio, pero no estudio tanto ( $2^{\circ}$ año, universidad de estratos bajos)

Similarmente a lo que ocurre con los estudiantes de la universidad de estratos bajos, en general los entrevistados de la universidad no-académica pluriclasista tienen una experiencia de ajuste de baja intensidad, caracterizada por la baja dificultad académica que perciben sus estudiantes. De esta manera, se corre el riesgo de perpetuar las deficiencias formativas heredadas de la experiencia escolar. Más aún, se evidencia una "cultura de la urgencia académica" caracterizada por la baja inversión de tiempo en los estudios durante la mayoría del periodo académico, concentrando dichos esfuerzos en los periodos cercanos a las evaluaciones.

Tomar el ritmo no me costó tanto, pero aprendí que de repente es necesario estudiar un poco en la casa, eso me di cuenta en la universidad, ya no basta con estudiar en la micro antes de la prueba, hay que estudiar un día antes o dos... esa es la diferencia con el colegio y eso aprendí ( $1^{\circ}$ año, universidad no-académica pluriclasista).

Por su parte, la experiencia de ajuste de la universidad de élite se da dentro de un contexto reconocido como altamente exigente. Esto se evidencia cuando los estudiantes señalan haber intensificado algunas de sus prácticas para enfrentar las demandas académicas de la institución. Aquí la fuerza está puesta en la intensidad, más que en las formas y estrategias de estudio.

Más investigación, más lectura, leer libros y que si antes no leía los libros igual podía responder y ahora si no leo los libros después en la pruebas no sé nada, es un nivel de dificultad mucho mayor, investigar cosas, hacer informes ( $2^{\circ}$ año, universidad de élite).

Los grados de integración académica no solo se observan en las experiencias de transformación positiva de las disposiciones 
86 LA EXPERIENCIA DE ESTUDIANTES DE CONTEXTOS VULNERABLES EN DIFERENTES INSTITUCIONES DE EDUCACIÓN SUPERIOR UNIVERSITARIA (IESU): RESULTADOS DE INVESTIGACIÓN - D. Leyton, A. Vásquez, V. Fuenzalida

académicas que han tenido los estudiantes entrevistados, sino también en la intensidad y tipo de compromiso con los estudios, los cuales se asocian significativamente a la cultura académica de las universidades.

\subsection{El compromiso con los estudios y la cultura académica}

A partir de las entrevistas se pueden diferenciar distintas formas de expresión de los niveles de compromiso en el espacio universitario. Por ejemplo, se puede identificar si las prácticas que expresan dichos compromisos se orientan hacia la acumulación de capital cultural institucionalizado (la obtención del diploma), o bien hacia la acumulación de capital cultural incorporado a través de una segunda socialización pedagógica, esta vez en la educación superior (la incorporación de disposiciones prácticas y aprendizajes profesionalesdisciplinares) (Bourdieu, 2001).

Si bien en general los estudiantes están ciertos de la importancia que tiene la educación universitaria como mecanismo de movilidad social a través de la obtención del título o credencial educativa, se pueden distinguir diferentes énfasis de ello en sus relatos. Por ejemplo, en el caso de la universidad académica pluriclasista se observa un alto compromiso con los estudios, expresado en sus disposiciones hacia el cumplimiento de las demandas académicas orientadas de forma más pronunciada hacia horizontes de referencia que están puestos en el proceso de aprendizaje y rendimiento académico, lo cual se evidencia en el reconocimiento de la importancia de desarrollar estrategias concebidas como necesarias para enfrentar con éxito los desafíos académicos.

Porque en la universidad tienes que tener un hábito de estudio para pasar los ramos... en la universidad con ir a clases no te basta, tienes que estar atenta a todo, a las tareas que te mandan los profesores o a las páginas que te sugieren o los textos que te sugieren, más los textos obligatorios, entonces tienes que tener un hábito $\left(5^{\circ}\right.$ año, universidad académica pluriclasista).

Este compromiso expresado por los estudiantes de dicha universidad se encuentra mediado por una conciencia de la situación 
de desventaja respecto de sus compañeros y también por la existencia de una cultura académica fuerte que pone en el centro el valor de "lo académico", lo cual promueve disposiciones orientadas hacia los estudios. De esta forma, dicha cultura fomentaría el desarrollo del "sentido del juego" a través de la incorporación de orientaciones intelectuales y sensibilidades propias de la situación de clase existente en dicha universidad (Bernstein, 1975).

Entonces siento que de alguna manera tenía que esforzarme el doble que los demás y la suerte que tuve que me encontré con gente que igual quería estudiar bien, hacerse responsable por lo que te toca estudiar e hice un grupo de estudio bacán y eso me ayudó porque no tenía idea de vocabulario ni de hacer una ficha de lectura ( $5^{\circ}$ año, universidad académica pluriclasista).

Por su parte, en el resto de las universidades se reportan compromisos relativamente altos orientados principalmente hacia la acumulación de capital cultural institucionalizado. Esto se asocia a la existencia de una "cultura credencialista" que acentúa el sentido del compromiso universitario en la obtención del título y sus posteriores retornos educativos. En este sentido, el compromiso con los estudios no logra distanciarse de la necesidad: los estudiantes se comprometen en la medida en que tal disposición contribuya a satisfacer, en el futuro, necesidades económicas y aspiracionales que hoy en día no poseen.

Tengo ganas de salir, trabajar y ganar mucha plata. A veces ya me doy cuenta de que ya pasó un semestre y el segundo semestre ya estamos terminando, ya se pasa muy rápido. También me preocupa un poco echarme ramos, pagar y seguir pagando, cuánto me voy a endeudar $\left(1^{\circ}\right.$ año, universidad no-académica pluriclasista)

Le estoy poniendo más empeño en lo que estoy haciendo porque igual me di cuenta de que me las farrié, entonces quiero un futuro mejor para mi hija y para mí, poder ayudar a mi familia y que mi hija tenga una buena educación. Que vaya a un colegio aunque tenga que pagar más alto, el poder pagarle y que también vaya a la universidad ( $4^{\circ}$ año, universidad de estratos bajos). 
88 LA EXPERIENCIA DE ESTUDIANTES DE CONTEXTOS VULNERABLES EN DIFERENTES INSTITUCIONES DE EDUCACIÓN SUPERIOR UNIVERSITARIA (IESU): RESULTADOS DE INVESTIGACIÓN - D. Leyton, A. Vásquez, V. Fuenzalida

En las universidades de estratos bajos el compromiso orientado hacia la acumulación de capital cultural institucionalizado se encuentra mediado por una cultura estudiantil que censura o traba las disposiciones académicas de algunos entrevistados, situación que repercute negativamente en sus posibilidades de integración académica. Este ethos cultural se observa en la baja disposición que poseen los estudiantes de contextos vulnerables para generar espacios que permitan la conversación y discusión en torno a las materias, o bien respecto de la constitución de grupos de estudio: más aún, en la universidad de estratos bajos la simultaneidad entre estudio y trabajo reproduce con mayor fuerza dicha cultura de la censura académica.

Claro, por eso te dije antes que estaba agradecido de haber vivido lo que viví para posterior a eso haber estudiado y haberme motivado a estudiar esta carrera, entonces veo que no es así con mis compañeros y eso de repente me choca ( $3^{\text {er }}$ año, universidad de estratos bajos).

Ya, tengo que estudiar y tengo que ponerle y voy a ser el mejor y todo el cuento. Al final me di cuenta por mis compañeros que hicieron indirectamente que yo no estudiara ( $1^{\text {er }}$ año, universidad no-académica pluriclasista).

Se sugiere que un compromiso en el cual prima la adquisición de capital cultural internalizado está asociado a una integración académica más intensa, expresada en el reconocimiento de la importancia de la adquisición de conocimiento y no solo en la obtención del título profesional. Dicho tipo de compromiso se ve posibilitado por un aspecto central del habitus institucional: la cultura académica, la cual se caracteriza aquí por los grados de exigencia que desafían a los estudiantes y, a su vez, por una cultura estudiantil que valora los procesos de aprendizaje en sí mismos. Dicho entorno socioinstitucional, junto con las ayudas económicas pertinentes, permite en estos estudiantes desarrollar compromisos con sus estudios, distanciándose de las necesidades vitales y su consecuente aspiración a superarlas. 
5.6. La identificación de espacios institucionales asociados a las experiencias académicas

A partir de las entrevistas se identifican espacios y prácticas institucionales que afectan la integración académica. Dentro de ellas se distinguen: la preocupación de los docentes por los estudiantes, la calidad de las prácticas docentes, la existencia de programas orientados al fortalecimiento de las habilidades académicas de los estudiantes de orígenes vulnerables y la infraestructura orientada a minimizar la falta de espacios y recursos apropiados de estudio en los hogares.

La mayoría de los estudiantes entrevistados de todas las universidades dan cuenta de que algunos de sus docentes demuestran preocupación por sus alumnos y perciben, en general, una buena calidad de sus profesores, siendo esto último más generalizado en los discursos de los entrevistados de la universidad académica pluriclasista, la cual de acuerdo con los datos encontrados presenta la mayor cantidad de docentes con postgrados.

Por otro lado, la preocupación de los docentes por sus estudiantes se basa en el reconocimiento de una disposición de algunos profesores por atender las dificultades académicas de los estudiantes entrevistados y/o en el establecimiento de relaciones de tipo socioafectivas.

Encuentro que tienen harto conocimiento los profesores y tienen harta disponibilidad para enseñar, igual como que uno le pregunta una y mil veces, y por lo menos los profesores que me han tocado son súper buenos (...) Incluso los profesores ofrecen ayudantía e incluso cuando uno los pilla en el patio les puede preguntar cualquier cosa ( $2^{\circ}$ año, universidad académica pluriclasista).

¿Cómo es tu relación con los profesores? Excelente ¿Es cercana? Sí, él ya me adoptó como hija, o sea, yo estoy en los ensayos de él con su grupo, así (hay) mucha confianza... No es como ir al colegio, en el colegio tienes que, si el profesor te escucha, decir hasta lo más mínimo "A ver ¿qué fue eso?" (como advertencia) ( $1^{\mathrm{er}}$ año, universidad de estratos bajos). 
90 LA EXPERIENCIA DE ESTUDIANTES DE CONTEXTOS VULNERABLES EN DIFERENTES INSTITUCIONES DE EDUCACIÓN SUPERIOR UNIVERSITARIA (IESU): RESULTADOS DE INVESTIGACIÓN - D. Leyton, A. Vásquez, V. Fuenzalida

No obstante, las experiencias de las relaciones de los profesores que muestran preocupación por sus estudiantes se refieren a casos de docentes específicos y no a la generalidad de ellos. En este sentido, no se observa una disposición institucional sistemática de los académicos por fortalecer las relaciones con los estudiantes. Ante esto, se puede señalar que los programas propedéuticos constituyen un mecanismo que permite compensar la falta de orientaciones institucionales que fortalezcan los contactos entre estudiantes y docentes, sobre todo a partir de la figura de los monitores o del mentor, los cuales operan como soportes académicos a través de la ayuda y monitoreo de sus rendimientos académicos (Erickson, McDonald y Elder, 2009).

Había un orientador que se preocupaba "¿Cómo te va? ¿Cómo te está yendo? ¿Necesitas ayuda?". En ese sentido se preocuparon harto de nosotros, de que nos fuera bien y que no dejemos la carrera botada ( $1^{\text {er }}$ año, universidad no-académica pluriclasista).

Finalmente, es importante destacar la importancia de la infraestructura de las universidades para enfrentar los desafíos académicos que se les presentan a los estudiantes de orígenes vulnerables. De las cuatro universidades seleccionadas, en tres de ellas los estudiantes destacan la infraestructura adecuada existente en sus instituciones. Sin embargo, los entrevistados de la universidad de estratos bajos perciben precarias condiciones de las instalaciones dispuestas para los estudios, como por ejemplo en las bibliotecas o en las salas de computación.

¿Hay computadores? ¿Hay biblioteca? Se supone, pero están todos malos, de cinco uno o dos están en funcionamiento, ni eso, el año pasado cuántas clases nos perdimos de computación porque los computadores están pésimos; aquí no tenemos cómo trabajar, aquí falta eso (...) lo encuentro el colmo, si uno está pagando para eso ( $1^{\text {er }}$ año, universidad de estratos bajos).

La existencia de una infraestructura adecuada es central si se piensa en estudiantes de condiciones vulnerables, puesto que ello permite que los alumnos cumplan con las demandas académicas, a pesar de encontrarse en una situación deficitaria, no solo en términos 
económicos, sino también por la falta de espacios en sus hogares, tornándose fundamentales para enfrentar con éxito la experiencia académica.

Por eso siempre estudio acá en la universidad... y aparte que las vecinas en las casas escuchan música ultra fuerte, ponen su reggaetón, su cumbia, ahora los wachiturros y los ponen tan fuerte que llegan a vibrar los vidrios, entonces imposible estudiar en la casa, cero posibilidades de estudiar allá, por eso ocupo tanto la biblioteca, los computadores para imprimir $\left(5^{\circ}\right.$ año, universidad académica pluriclasista).

\section{Reflexiones finales}

Las experiencias sociales y académicas de los estudiantes de contextos vulnerables se encuentran atravesadas por diferentes tensiones centrales, las cuales se configuran de forma distinta según ciertas dimensiones del habitus institucional de las universidades.

Una primera tensión se observa en el ingreso a la universidad, el cual se encuentra marcado por el sentimiento de desigualdad ante los compañeros y por una experiencia de desclasamiento que distancia a los estudiantes de contextos vulnerables de sus orígenes sociales. La experiencia de desclasamiento emerge de forma más violenta en la universidad de élite, en donde las posibilidades de integración se pueden hacer efectivas en la negación y ocultación de los orígenes sociales.

Una segunda tensión central se encuentra en la propia relación entre las experiencias de integración social y la integración académica. Ante la desventaja académica con la cual ingresan a la universidad, los estudiantes de orígenes vulnerables se ven forzados a cancelar las posibilidades de expandir e intensificar la participación e interacción social, sintiendo muchas veces que dichas instancias se encuentran fuera de su alcance. Esto contribuye a la reproducción de la clausura social, en el caso de las universidades pluriclasistas, o bien al asilamiento e instrumentalización de las relaciones sociales, en el caso de la universidad de élite. 
No obstante, cuando se logra articular una mayor heterogeneidad social, sin excluir en esta estrategia de selección a aquellos estudiantes herederos de altos capitales culturales, dicha tensión entre la experiencia social y académica pareciera disminuir, abriéndose la posibilidad de establecer relaciones más democráticas, racionales y tolerantes y generando un espacio propicio de socialización académica y ciudadana. De esta manera, adquieren relevancia mecanismos de selección que permitan incorporar a estudiantes de contextos vulnerables sin abdicar a la excelencia académica, por ejemplo, considerando alternativas de ingreso distintas de la PSU, lo cual hace más eficiente y racional la selección de sus estudiantes. Esto debido a que dichos mecanismos alternativos, como las notas en la enseñanza media permiten estimar los rendimientos y talentos de forma contextualizada, aminorando los efectos de la herencia social.

Efectivamente, las experiencias sociales y académicas más exitosas se dan en aquellas instituciones de educación superior que poseen un habitus institucional que se hace cargo, en alguna medida, de todas las funciones sociales de la educación: pluralización de la estructura de clase de sus estudiantes, incorporación y ayuda para los estudiantes de contextos vulnerables y prevalencia de una cultura académica fuerte. A partir de dicha cultura académica, en la universidad académica pluriclasista fue posible observar niveles de integración académica aceptables, caracterizados por una transformación importante de sus disposiciones de estudio y un compromiso centrado más en el proceso de aprendizaje que en la obtención del título universitario.

Teniendo en cuenta los párrafos precedentes respecto de la integración social y académica de los estudiantes se puede decir que la universidad no solo tiene la tarea de proveer habilidades para la incorporación de sus estudiantes al mercado laboral, sino que también tiene la tarea de ofrecerles y promover para ellos mayores oportunidades, seleccionando a sus estudiantes de forma eficiente de acuerdo con sus habilidades e intereses y promoviendo su compromiso y habilidades relevantes para el ejercicio de una ciudadanía activa (Van de Werfhorst y Mijs, 2010). 
Se puede destacar una última tensión observada en la débil integración social y académica de los estudiantes de la universidad de estratos bajos. Si bien existe sentido de correspondencia, ello no puede entenderse como un indicador de integración, ya que esta se encuentra mediada por un habitus institucional débil académicamente, sumado a la fragmentación espacial vivida en dicha universidad. Este sentido de correspondencia, si bien genera cierto sentimiento de confort entre los estudiantes de contextos vulnerables, no significa una integración académica fuerte y tampoco el desarrollo de mayores grados de contacto y vínculo social con sus compañeros. De esta manera, la correspondencia reproduce sus identidades en cuanto trabajadores, pero constriñe las posibilidades de desarrollar identidades académicas fuertes y vínculos sociales significativos. Tomando en cuenta dicha evidencia, se torna problemático concebir como universidades inclusivas a aquellas que promueven una política de acceso orientada a estudiantes de contextos vulnerables, homogeneizando el espacio social universitario, puesto que, como se ha señalado, este tipo de estrategia segmenta y conforma guetos socioeducativos, imposibilitando el desarrollo de aprendizajes de nuevos códigos culturales y experiencias socioculturales más diversas y democráticas.

Finalmente, es importante señalar que las instituciones debieran responsabilizarse por los efectos que puede tener, en las experiencias de los estudiantes de contextos vulnerables, el sentimiento de desventaja que ellos viven respecto de sus compañeros. Asumir esa responsabilidad representa tanto una oportunidad (para fortalecer sus niveles de integración) como una falencia (si es que se deja a la agencia individual el gestionar dicha experiencia). En este sentido, la promoción de programas de transición educativa hacia la educación superior, como los programas propedéuticos, parecen ser valorables instancias de apoyo y monitoreo para aquellos estudiantes que ingresan a la universidad en condiciones desiguales (Castillo y Cabezas, 2010).

No obstante, la inclusión de dichos programas en políticas de transición educativa a nivel macroestructural es condición necesaria -no suficiente- para dar estabilidad y sustentabilidad a los programas 
94 LA EXPERIENCIA DE ESTUDIANTES DE CONTEXTOS VULNERABLES EN DIFERENTES INSTITUCIONES DE EDUCACIÓN SUPERIOR UNIVERSITARIA (IESU): RESULTADOS DE INVESTIGACIÓN - D. Leyton, A. Vásquez, V. Fuenzalida

ya existentes y para promover dichas innovaciones institucionales en el resto de las universidades. La construcción de este tipo políticas, que considere las múltiples complejidades presentes en las experiencias de los estudiantes, como algunas de las descritas aquí, puede contribuir a suavizar y hacer probables transiciones que de otra forma serían inestables, tensionantes o simplemente improbables (Sackman y Wingens, 2003). De lo contrario, parafraseando a Bourdieu, nada sería más inocente que el "dejar hacer".

\section{Referencias bibliográficas}

Araujo, K. y Martuccelli, D. (2011). La inconsistencia posicional: un nuevo concepto sobre la estratificación social. Revista CEPAL, Abril (103), pp.165-178.

Ayalon, H., Grodsky, E., Gamoran, A. y Yogev, A. (2008). Diversification and inequality in higher education: a comparison of Israel and the United States. Sociology of Education, 81(3), pp. 211-241.

Ball, S. J., Davies, J., David, M. y Reay, D. (2002). Classification and judgement': social class and the 'cognitive structures' of choice of higher education. British Journal of Sociology, 23(1), pp. 51-72.

Bernstein, B. (1975). Class, codes and control. Volumen III. Primera Edición. London: Routledge and Kegan Paul.

Bourdieu, P. (2001). Sobre el poder simbólico. En: Andrés García Inda (Org.): Poder, Derecho y Clases Sociales, Cap. II. Bilbao: Desclée de Brouwer.

Bourdieu, P. y Passeron, J.C. (2003). Los Herederos. Los estudiantes y la cultura. I ed. Buenos Aires: Siglo XXI.

Brunner, J. y Uribe, D. (2007). Mercados Universitarios. El nuevo escenario de la Educación Superior. Santiago de Chile: Universidad Diego Portales.

Brunner, J. (2009a). Educación Superior en Chile: instituciones, mercados y politicas gubernamentales (1967-2007). Santiago de Chile: Universidad Diego Portales.

Brunner, J. (2009b). Tipología y características de las universidades chilenas. Santiago de Chile: Centro de Políticas Públicas Comparadas en Educación. Universidad Diego Portales.

Castillo, J. y Cabezas, G. (2010). Caracterización de jóvenes primera generación en educación superior. Nuevas trayectorias hacia la equidad educativa. Revista Calidad en la educación, 32, pp. 44-76. 
Canales, M. (Coord.) (2006). Metodologías de investigación social. Introducción a los oficios. Santiago de Chile: LOM.

Canales, A. y de los Ríos, D. (2007). Factores explicativos de la deserción universitaria. Revista Calidad en la Educación, 26, pp. 173-201.

Canales, A. y de los Ríos, D. (2009). Retención de estudiantes vulnerables en la educación universitaria. Revista Calidad en la Educación, 30, pp. 50-83.

Consejo Nacional de Educación (2011). Índice Estadísticas y Bases de Datos (actualizados). Retención en el Sistema de Educación Superior: Seguimiento de las cohortes 2004 al 2008. Disponible en: http:// www.cned.cl/public/Secciones/SeccionIndicesEstadisticas/indices_ estadisticas_retencion.aspx

Cooke, R., Barkham, M., Audin, K. y Bradley, M. (2004). How social class differences affect students' experience of university. Journal of Further and Higher Education, 28 (4), pp. 407-421.

Cox, C. (1987) Clases y transmisión cultural. Santiago de Chile: CIDE.

Crozier, G., Reay, D., Clayton, J., Colliander, L. y Grinstead, J. (2008). Different strokes for different folks: diverse students in diverse institutions - experiences of higher education. Research Papers in Education, 23, pp. 167-177.

Donoso, S. y Cansino, V. (2007). Caracterización socioeconómica de los estudiantes de educación superior, Revista Calidad en la Educación, 26, pp. 205-244.

Erickson, L. D., McDonald, S. y Elder, G. (2009). Informal mentors and education: complementary or compensatory resources? Sociology of Education, 82(4), pp. 344-367.

Forsyth, A. y Furlong, A. (2003). Access to higher education and disadvantaged young people. British Educational Research Journal, 29(2), pp. 205-225.

Furlong, A. y Cartmel, F. (2009). Higher education and social justice. New York: Open University Press.

González, L., Uribe, D. y González, S. (2005). Estudio sobre la repitencia, deserción en la educación superior chilena. Instituto Internacional para la Educación Superior en América Latina y el Caribe, Disponible en: http:// unesdoc.unesco.org/images/0014/001400/140087s.pdf

Gobierno de Chile. Instituto Nacional de la Juventud (2006). V Encuesta Nacional de Juventud. Disponible en: http://www.injuv.gob.cl/portal/ wpcontent/files_mf/1346363423_magicfields_archivo_1_1.pdf 
96 LA EXPERIENCIA DE ESTUDIANTES DE CONTEXTOS VULNERABLES EN DIFERENTES INSTITUCIONES DE EDUCACIÓN SUPERIOR UNIVERSITARIA (IESU): RESULTADOS DE INVESTIGACIÓN - D. Leyton, A. Vásquez, V. Fuenzalida

Gobierno de Chile. Instituto Nacional de la Juventud (2010). VI Encuesta Nacional de Juventud. Disponible en: http://www.injuv.gob.cl/portal/ wp-content/files_mf/sextaencuestanacionaldejuventud.pdf

Jiménez, C. (2011) ¿Empobrecimiento o desclasamiento? La dimensión simbólica de la desigualdad social. Trabajo y Sociedad, XV (17), pp. 49-65.

Koskinen, K. (2007). Labour market succes of young european graduates. Seminar of youth employment and the future of work. European Union. Disponible en: http://youthpartnership.coe.int/youthpartnership/ documents/EKCYP/Youth_Policy/docs/Employment/Chapter_2_ Katariina_Koskinen.pdf

Lehmann, W. (2007). 'I just didn't feel like I fit in': The role of habitus in university dropout decisions. Canadian Journal of Higher Education, 37, pp. 89-110.

Lehmann, W. (2009). University as vocational education: working-class students' expectations for university. British Journal of Sociology of Education, 30, pp. 137-149.

Lizzio, A., Wilson, K. y Simons, R. (2002). University students' perceptions of the learning environment and academic outcomes: implications for theory and practice. Studies in Higher Education, 27(1), pp. 27-52.

McDonough, P. (1997). Choosing colleges: how social class and schools structure opportunity. New York: State University of New York.

Meneses, F., Rolando, R., Valenzuela, M. y Vega, M. (2010). Ingreso a la educación superior. La experiencia de la cohorte de egreso 2005. Sistema Nacional de Información de la Educación Superior (SIES) y División de Educación Superior del MINEDUC. En: http://www.divesup.cl/ images/archivos/Publicaciones/ingreso\%20a\%20la\%20educacin\%20 superior.pdf

Metcalf, H. (2003). Increasing inequality in higher education: the role of term-time working. Oxford Review of Education, 29(3), pp. 315-329.

Organización para la Cooperación y el Desarrollo Económico (2009). La educación superior en Chile. Revisión de Políticas Nacionales de Educación. OCDE. Banco Mundial. Disponible en: http:// mt.educarchile.cl/MT/jjbrunner/archives/La\%20Educaci\%F3n\%20 Superior\%20en\%20Chile0407.pdf

Pascarella, E. y Terenzini, P. (1979). Interaction effects in Spady's and Tinto's conceptual models of college dropout. Sociology of Education, 52, pp. 197-210. 
Pascarella, E., Duby, P. y Iverson, B. (1983). A test and reconceptualization of a theoretical model of college withdrawling in a commuter institution setting. Sociology of Education, 56, pp. 88-100.

Reay, D. (1998). "Always knowing" and "never being sure": familiar and institutional habituses and higher education choice. Journal of Education Policy, 13(4), pp. 519-529.

Reay, D., David, M. y Ball, S. (2001). Making a difference?: Institutional habituses and higher education choice. Sociological Research Online, 5(4). En: http://www.socresonline.org.uk/5/4/reay.html

Reay, D., Crozier, G. y Clayton, J. (2010). "Fitting in" or "standing out": working-class students in UK higher education. British Educational Research Journal, 36(1), pp. 107-124.

Sackman, R. y Wingens, M. (2010). From transitions to trajectories. Sequence types. En Heinz, W. \& Marshall, V (eds.) Social dynamics of the life course. Transitions, Institutions and interrelations (pp. 93-115). New York: Aldine de Gruyter.

Stuber, J. (2011) Inside the college gates: how class and culture matter in higher education. Lanham, Md.: Lexington Books.

Thomas, L. (2002). Student retention in higher education: the role of institutional habitus. Journal of Education Policy, 17(4), pp. 423-442.

Thomas, L. y Quinn, J. (2007). First generation entry into higher education. Maidenhead: Open University Press.

Thrupp, M. (1999). Schools making a difference: Let's be realistic! Buckingham: Open University Press.

Tinto, V. (1993). Leaving College: Rethinking the causes and cures of student attrition. Chicago: University of Chicago.

Van de Werfhorst, H. y Mijs, J. (2010). Achievement inequality and the institutional structure of educational systems: a comparative perspective. Annual Review of Sociology, 36(1), pp. 407-428.

Recibido: 01/10/2012

Aceptado: 26/11/2012 